\title{
Construir la escena local. Apuestas y prácticas en las artes visuales de la ciudad de La Plata
}

\section{Artículo de investigación}

\section{Matías David López}

Universidad Nacional de La Plata, Argentina matiasdlopez@yahoo.com.ar

Recibido: 27 de octubre de 2017

Aprobado: 15 de marzo de 2018

Cómo citar este artículo: López, Matías David (2018). Construir la escena local. Apuestas y prácticas en las artes visuales de la ciudad de La Plata. Calle 14: revista de investigación en el campo del arte 13(24) pp. 450468. DOI: https://doi.org/10.14483/21450706.13538 



\begin{abstract}
Resumen
A partir del concepto de "escena artística", este artículo indaga en las características de los proyectos culturales de la ciudad de La Plata: los modos de gestión, las formas de articulación y las políticas estéticas. El análisis se focaliza en algunas situaciones y actores de la escena de las artes visuales para interrogar por la emergencia y potencialidad de los modos de producir y gestionar desde las prácticas locales alternativas, indagando en sus relaciones con las políticas culturales. Para ello, se recurre a las observaciones, mapeos y entrevistas en profundidad reveladas en el trabajo de campo. El objetivo es contribuir al análisis de los procesos culturales contemporáneos.
\end{abstract}

\title{
Palabras claves
}

Artes visuales, escena artística, producción y gestión cultural, La Plata.

\section{To build the local scene. Bets and practices in visual arts in the city of La Plata}

\begin{abstract}
From the concept of "artistic scene", this article explores the characteristics of cultural projects in the city of La Plata: their modes of management, forms of articulation and aesthetic policies. The analysis focuses on some situations and actors of the visual arts scene to question the emergence and potentiality of ways of producing and managing from alternative local practices, inquiring into their relations with cultural policies. To do this, it uses the observations, mappings and in-depth interviews revealed in the fieldwork. The objective is to contribute to the analysis of contemporary cultural processes.
\end{abstract}

\section{Keywords}

Visual arts, artistic scene, cultural production and management, La Plata.

Construire la scène locale. Paris et pratiques dans les arts visuels de la ville de La Plata

\section{Résumé}

Depuis le concept de « scène artistique », cet article explore les caractéristiques des projets culturels de la ville de La Plata : les modes de gestion, les formes d'articulation et les politiques esthétiques. L'analyse se concentre sur certaines situations et acteurs de la scène des arts visuels pour interroger l'émergence et la potentialité des modes de production et de gestion à partir de pratiques locales alternatives, en étudiant leurs relations avec les politiques culturelles. Pour ce faire, il utilise les observations, les cartographies et les entretiens approfondis révélés dans le travail de terrain. L'objectif est de contribuer à l'analyse des processus culturels contemporains.

\section{Mots clés}

Arts visuels, scène artistique, production et gestion culturelle, La Plata.

\section{Construir a cena local. Apostas e práticas nas artes visuais da cidade de La Plata}

\section{Resumo}

A partir do conceito de "cena artística", este artigo explora as características dos projetos culturais da cidade de La Plata: os modos de gestão, as formas de articulação e as políticas estéticas. A análise enfoca algumas situações e atores da cena das artes visuais para questionar o surgimento e a potencialidade das formas de produzir e gerenciar a partir de práticas locais alternativas, investigando suas relações com as políticas culturais. Para isso, utiliza as 
observações, mapeamentos e entrevistas em profundidade reveladas no trabalho de campo. 0 objetivo é contribuir para a análise dos processos culturais contemporâneos.

\section{Palavras chaves}

Artes visuais, cena artística, produção e gestão cultural, La Plata.

\section{Maillallachiska:}

Tapuchinakumi ka kilkapi imasam kawankuna paikuna nukanchita pai kunimi kikin aidaringa, kawanakumi tapuchinakumi ikuti, ruraspa, kilkaspa maskalla maimanda ka mana, kai suma, kaugsai tukuringapa

\section{Rimangapa Ministidukuna:}

Kawachispa ruraikuna, mailla mailla ruraska, tukuikunamanda kawai, chasa suti alpa, chagta kulki. 


\section{Coordenadas}

Este artículo indaga en la escena de las artes visuales de la ciudad de La Plata (Provincia de Buenos Aires, Argentina). Pretende llegar a un análisis situado y relacional de algunas de las prácticas y los proyectos culturales que conforman dicha escena, de sus inscripciones en los contextos de producción y gestión cultural contemporáneos y, por último, de los modos de vincularse y crear tensiones con las políticas culturales estatales. La indagación de estas cuestiones se concentra en tres casos de estudio: el productor-gestor Luxor, el colectivo Síntoma y la galería Cösmiko.

Estas reflexiones forman parte de un trabajo de investigación en curso. Para ampliar la caracterización de la escena de las artes visuales, la misma es considerada en determinado contexto social, político y cultural (principalmente entre los años 2010-2015) que configuró nuevas demandas, inquietudes y espacios para las prácticas culturales de la ciudad y del país ${ }^{1}$. Entre otras cosas, se destaca una manera específica de pensar el campo del arte en sus formas contemporáneas y una intención cada vez más fuerte de "vivir de la cultura y el arte"; tanto de la producción como de la gestión y la circulación. Es así que algunos actores culturales locales comenzaron a proyectar esta intención a partir del desarrollo de pequeños emprendimientos productivos y autogestionados. De este modo, se puede localizar en un nuevo mapa a ciertas apuestas, prácticas y derivas que son parte de la escena cultural local.

El objetivo, entonces, es trabajar estas cuestiones de modo exploratorio y con un registro ensayístico, a partir de algunos de los diagnósticos y análisis de las experiencias culturales vinculadas a las artes visuales en La

$1 \quad$ Uno de los entrevistados durante el trabajo de campo identificó este período como un momento en el cual operó una "normalización" y se configuró cierto "bienestar social". Podemos caracterizar que se abrió una nueva situación, marcada por cierta estabilidad en la que un sector de clase media de la sociedad platense - hasta no hace tanto empobrecida - se empoderó de recursos y comenzó a plantearse la posibilidad de vivir de sus propios emprendimientos y proyectos colectivos o individuales, por ejemplo, vivir de la producción y gestión de la cultura y las artes. Esta situación se diferencia de períodos previos en los cuales estos emprendimientos eran imposibles de proyectar. Consideramos que estas son algunas de las condiciones de posibilidad para ciertas prácticas ligadas a la producción artística y a la emergencia de un nuevo campo de prácticas culturales en la ciudad. En relación con ello, hay que resaltar también los proyectos de "reconversión urbana", que están produciendo profundas transformaciones en la ciudad.
Plata $^{2}$. Al respecto, se viene reflexionando en encuentros, publicaciones, conversaciones e intervenciones públicas ${ }^{3}$. La idea es, a partir de algunas hipótesis, poder esbozar propuestas que contribuyan con el desarrollo de una analítica de los procesos y experiencias culturales contemporáneos.

\section{Sobre las escenas culturales}

Junto con la noción de "escena", en este artículo se invocan también otros conceptos productivos. Entre ellos, el de "campo cultural y artístico", presentado desde la perspectiva sociológica de Pierre Bourdieu $(2002,2014)$ para analizar agentes, posiciones y estrategias dentro de un sub-espacio del campo intelectual. Asimismo, Raymond Williams (2009) aporta algunos desarrollos conceptuales sugerentes sobre lo "emergente" y la "formación cultural". Con todo, se otorga primacía a la idea de "escena" por tratarse de un "concepto nativo" (como se verá más adelante) y porque es una noción flexible que puede alcanzar mayor

2 Existe una gran diversificación de prácticas culturales y artísticas que pueden ser definidas como "escenas" de la ciudad. Las artes visuales conforman una "escena" en la que podemos englobar actores y prácticas heterogéneas que van desde muestras de "artistas visuales" y galerías independientes a talleres de producción visual y de clínica de obra; desde prácticas curatoriales hasta la "movida" de grafiteros e interventores urbanos. Es decir, un gran número de prácticas vinculadas con el arte contemporáneo, la instalación, lo plástico, lo gráfico y lo fotográfico. También existen en la ciudad otras escenas, por ejemplo, la escena de las artes performáticas, escénicas y de la danza; la escena musical y la escena editorial y literaria. Algunas de estas escenas artísticas de La Plata son indagadas en los trabajos de Saez $(2015,2016)$ y Boix $(2013,2016)$. Muchas veces se trata de escenas que se pueden delimitar, pero también se pueden reconocer cruces, convites y, quizá, apuestas y proyectos en común. A su vez, analíticamente podemos identificar que cada escena cultural está compuesta por diferentes "circuitos" que tienen que ver principalmente con afinidades y estilos compartidos. En la escena de las artes visuales el circuito de galerías, prácticas curatoriales y espacios y talleres de arte se diferencia del circuito del street art, sin embargo, en estos casos existen cruces y cuestiones compartidas, que podemos identificar en algunos lugares de circulación y apropiación en la ciudad.

3 En trabajos anteriores se han abordado algunos temas de este artículo y forman parte de la investigación en curso: López, 2013, 2015, 2017. Entre los años 2013-2015 realicé una columna radial semanal sobre las artes visuales de la ciudad en el programa "La fábrica de manteca" de FM Provincia. Asimismo, la sección reseñas de Síntoma es un completo espacio de reflexiones sobre la escena local de las artes visuales (disponible en http://issuu.com/sintoma). Desde el 2015 la revista boba realiza un intenso trabajo de reflexión sobre el arte contemporáneo -enfocándose en las artes visuales-y en el relevamiento de las escenas locales de arte del país; véase www.boba.com.ar. 
operatividad y especificidad temática que las otras dos nociones mencionadas. Esta noción de "escena" ¿abre la puerta para comprender los procesos culturales y artísticos contemporáneos desde la idea de nueva "clase creativa"? Se considera, en principio, que no hay una correspondencia directa, aunque no se anula la posibilidad de cierta articulación. Se puede observar que existe una batería de nociones que pueden retener cierto interés, así como potencial explicativo pero que deben ser trabajadas y confrontadas desde casos concretos y sus especificidades. Por contrapartida, comporta un riesgo dar cierta idea de "puesta en escena", "teatralización" (o escenificación) de los procesos sociales y de las prácticas culturales en particular, es decir, abonar a una lógica representacional de la vida que, claramente, no está en el foco de interés.

Con la intención de construir cierta definición conceptual de la "escena", se entiende a la misma como una zona más o menos delimitable de circuitos, espacios, prácticas y actores que, aunque heterogéneos, comparten ciertas inquietudes a iniciativas. De este modo, por escena de las artes/escena artística se hará referencia a un espacio específico y plural de prácticas artísticas que van tejiendo cuestiones en común. Dos parámetros para determinar una escena serán su localización geográfica — una ciudad-y su especificidad en la producción, el lenguaje de las artes y los procedimientos que utilizan (por ejemplo, artes visuales, la danza y las artes performáticas, la música folclórica, el rock indie).

Pero se reconoce que una "escena" no se agota en estos elementos. Es, por lo tanto, un campo a ser mapeado e interpretado constantemente en el trabajo de campo y en el ejercicio de reflexión, para lo que resulta fundamental relevar actores, dinámicas, circuitos, debates, discursos, sensibilidades, modos de hacer y de ser, concebir y significar. De esta manera, y entendiendo desde un sentido más amplio la investigación de prácticas y procesos culturales, se hace necesario recuperar las preguntas, los saberes y relatos de los protagonistas que "des-centran" la mirada del investigador y reconocen así la "intemperie" como lugar desde donde pensar (Martín-Barbero, 2004, pp. 14-15).

En tal sentido, las inquietudes compartidas de una "escena local de artes visuales", pueden ser reconocidas a partir de espacios recurrentes y validados para la circulación de obras, proyectos y actores ${ }^{4}$, una red de discursos que hablan sobre tendencias y sobre espacios y actores concretos (narraciones y discursos en los que se puede inferir una conversación y formas de conversar en común), dinámicas organizativas y estrategias de visibilidad, así como posicionamientos y vínculos diversos con lo institucional.

Sin embargo, como se refirió antes, la idea no es descartar a priori los conceptos de "campo cultural" y "formación cultural". Se puede plantear una tríada conceptual en la que adquieren utilidad descriptiva y analítica al presentar diferencias de escalas, dimensiones e intensidades. A grosso modo, se puede decir que de la "escena" (cierto nivel microsocial de prácticas culturales con similitudes que se conectan) se puede llegar analíticamente a un "campo cultural" (ciertos niveles de estructuración donde se pueden comprender dinámicas de relaciones - luchas por la legitimidad, conflictos de intereses, formaciones discursivas- en el tiempo y el espacio social) pasando por una "formación cultural" emergente (como tendencias renovadoras de la cultura en un momento específico). Todas ellas están atravesadas por ideas vinculadas a la creatividad y a la producción cultural. En esta articulación se reconoce que no se trata de términos antagónicos ni superpuestos, sino que se pueden complementar principalmente en cuanto a escala: una escena local de artes visuales que dialoga con otras escenas artísticas, que integra un campo cultural local, regional o nacional y que pueden ser parte de unas formaciones que movilizan "lo emergente". Otra noción relacionada será la de "circuitos"

4 A partir de un mapeo realizado en la investigación en curso, se
identificaron (entre el período 2010-2017) en la ciudad una veintena
de espacios de exhibición y exposición, entre alternativos y estatales,
ligados a las "artes visuales". En promedio se inauguran entre siete y
diez muestras por año en cada uno y en casi todos se realizan mues-
tras con venta de obra. Algunos de esos espacios - galerías, casas
culturales, espacios de arte, centros culturales, salas y museos muni-
cipales y provinciales- son: Cösmiko, Trémula, Siberia, Residencia
Corazón, Damme, Búm, Oro, La Salita (En eso estamos), Dionisia,
Tormenta salvaje, Vincent, El hormiguero, La Grieta, Caleidoscopio,
Victoria V, Obrador 45, C`est la vie, Club Alborada, Azul un Ala, Zule,
Ramos generales, Ansia (entre los alternativos) y Microespacio (que
integra el Museo Provincial de Bellas Artes), Centro Islas Malvinas,
Mumart, Macla y Prosecretaría de Cultura de la UNLP (entre los esta-
tales). También aparecieron otras iniciativas de visualización y articu-
lación: Cama elástica, Cero Diagonal, Agenda Zaz!, MUCA, la muestra
"F.D.A.C.M.A. Seccional La Plata", la intervención "La Multisectorial” y
el "Encuentro Local de Espacios y Colectivos vinculados a las Artes
Visuales" (realizado en 2013 ). Algunos espacios alternativos de galería
dejaron de funcionar en los últimos años: Mal de Muchos (fines del
2014), club Alborada (solo hace muestras de forma intermitente),
Trémula y Tormenta Salvaje (diciembre de 2016).


que puede servir para detectar y especificar aún más diversos recorridos y circulaciones que realizan los actores participantes de una misma escena cultural o artística.

Con el empleo de estas nociones se busca dirigir el foco hacia el relevamiento de apuestas y proyectos locales, relatos y discursos "menores" de la producción cultural y artística contemporánea. A ello se suma la necesidad de cruzarlos con situaciones y entramados estructurantes de la cultura, así como con las formaciones culturales alternativas o hegemónicas. Esta mirada pretende distanciarse de cierta perspectiva vinculada a las "bellas artes" y al canon artístico y estético, presente aún en las instituciones "promotoras" de la cultura y en aquellas que pretenden ser formadoras en artes, así como en ciertos discursos legitimados para hablar sobre "las cosas del arte".

Para ampliar la noción de escena, y comenzar un primer acercamiento a su operacionalización en el caso de La Plata, se puede recurrir a los aportes de Nelly Richard en su indagación sobre la denominada "Escena de Avanzada" ${ }^{5}$. Para esta autora, esa escena estuvo conformada por "micro-políticas del significante" que entre otras características, llevó adelante exploraciones en el lenguaje, los formatos y géneros y produjo a su vez una "espacialidad alternativa" (Richard, 2006, 2007). Si bien se trata de diferentes contextos sociopolíticos e históricos y situaciones divergentes respecto al arte, esta propuesta de Richard sirve para pensar de qué modo se renueva la utilización de los lenguajes y sus herramientas para desandar las prácticas artísticas y la dispersión de las estéticas. A la vez, contribuye para pensar cómo se generan espacios alternativos de activación desde prácticas situadas. Por último, sirve para comprender de qué manera en un momento determinado se puede generar una trama en la que convergen prácticas y actores culturales. En la escena de las artes visuales de La Plata, la cuestión de los lenguajes y las estéticas, actualmente se presenta tensionada -entre otros elementos - por una insistencia con la pintura de caballete, la ilustración y el dibujo de pequeño y mediano formato - formatos más accesibles para la venta en esta ciudad y presentados en cuadros o láminas-, una vuelta a las formas de lo manual-artesanal y el trabajo

En el análisis de Richard, la "Escena de Avanzada" forma parte de la resistencia cultural de finales de la década del 70 frente a la dictadura chilena y, a su vez, reformula el nexo entre "arte" y "política" alejándose y discutiendo el "repertorio ideológico de izquierda" (Richard, 2007). de taller (el impreso, el grabado, la estampa, la serigrafía, el calado, la fotografía analógica), y la instalación con utilización de los lenguajes sonoro y audiovisual y de tecnologías digitales atravesada fuertemente por lo conceptual y el trabajo de investigación. A continuación, se plantean algunas cuestiones para pensar las escenas artísticas en La Plata. Esta caracterización se relaciona con las formas de gestión, los modos de asociación y encuentros y las políticas estéticas que se configuran localmente.

\section{Las formas de gestión}

La palabra "gestión" no ha gozado de buena reputación en los espacios culturales, los productores y artistas de La Plata, a menos que se la piense como "autogestión", en cuyo caso ha funcionado como idea-fuerza potente que mueve muchas de las experiencias culturales, aunque sus definiciones varias veces sean amplias, esquivas o incompletas: desde "valernos por nosotros mismos" hasta "conseguir y manejar nuestros propios recursos", pasando por utilizarla como sinónimo de autonomía y una definición de principios ético-políticos. En cuanto a la idea de "gestión" — a secas - comenzaron a aparecer algunas experiencias y situaciones novedosas que hacen repensarla más allá del aura tecnocrática que la rodea. Las sospechas y críticas muchas veces han sido fundadas: el peligro de desplazar los proyectos -es decir, las ideas que los impulsan, las prácticas casi siempre colaborativas que las activan, las producciones hechas desde la creatividad- hacia (solamente) la lógica comercial de "vender", "lucrar con la cultura y el arte". Es decir, caer en situaciones donde la potencia de los proyectos culturales se podría anular por otras prioridades comerciales y recaudatorias. En las escenas culturales de la ciudad hay modos (en plural) de gestión. Prácticas de gestión diversas que, sobre todo cuando se trata de proyectos colectivos, priorizan las ideas de "autogestión", y en algunos casos despuntan desde ahí iniciativas para que sus integrantes puedan vivir de la producción y/o gestión y circulación cultural ${ }^{6}$. Sin embargo, en esta situación de nuevos debates y prácticas se puede afirmar —con algunas excepciones- que en las galerías y en los espacios dedicados a las artes visuales son los lugares que menos trabajadas se presentan estas cuestiones.

6 En los proyectos culturales que tienen "una cabeza" o un
par de integrantes - sea "dueño/a" o "gestor/a" del espacio o del
emprendimiento- esta cuestión de vivir de la producción, y principal-
mente, de la gestión del arte y la cultura queda mucho más clara que
en los proyectos un poco más numerosos. En parte, por una ecua-
ción simple: los recursos y el dinero que ingresan se dividen entre un
mayor número de personas.


De este modo, al relevar las situaciones y los fenómenos ligados a la escena local de artes visuales? ${ }^{7}$ encontramos que las preguntas por la gestión comienzan a estar presentes sobre todo en 1) una incipiente mirada de profesionalización de las prácticas culturales - tanto en la producción como en la circulación y la gestión-y 2) los intentos y esfuerzos que plantean "vivir del arte y la cultura", sea como productor-artista, y/o como gestor de espacios o de producciones de otros, como comunicador y divulgador cultural, como curador y/o comentarista de arte.

Estos intentos por desandar ideas y prácticas de profesionalización y de "vivir de la cultura y el arte", en el día a día, se mueven en acciones un tanto precarias para encarar muchos de los proyectos, tanto individuales como colectivos. Algunos de los siguientes puntos críticos pueden ser pensados para todas las escenas de la ciudad: por un lado, la poca sistematicidad de las acciones emprendidas, ya que se mueven principalmente por la fuerza de la voluntad individual o colectiva de los involucrados (por ejemplo, cuesta recuperar una memoria de lo construido). Por otro, se puede reconocer una ausencia de diálogos cruzados y sostenidos entre saberes y prácticas de las artes y la economía (por ejemplo, el saber académico y profesional sobre la gestión no tiene injerencia en los espacios y prácticas culturales). Distanciados como "mundos aparte" la cultura y la economía, la producción cultural y el desarrollo local actualmente no tienden lazos en la ciudad. Solo se desarrolla principalmente -en las iniciativas privadas y autogestivas- una economía de subsistencia personal o grupal a pequeña escala de

$7 \quad$ Algunas de las prácticas cada vez más cotidianas y estables son la venta de obra a pequeña escala (de manera directa o con intermediarios como algunas galerías de forma limitada); la apertura de convocatorias abiertas para muestras en las galerías, el cada vez mayor caudal de artistas que se presenta a dichas convocatorias locales; la búsqueda de mayor visualización (tanto institucional como mediática) de productores, curadores y galeristas; la cada vez más sostenida participación en eventos artísticos y convocatorias estatales y privadas, y de escalas locales, provinciales, nacionales e internacionales (por ejemplo, ArteBA, Arte Joven de la ciudad de Buenos Aires, subsidios y becas del Fondo Nacional de las Artes, Bienal Universitaria de Arte y Cultura, La Noche de los Museos, Microespacio dentro del Museo Provincial de Bellas Artes, premios del Salón Provincial de Arte Joven y de Artes Plásticas, participación en clínicas y residencias artísticas y en bienales y muestras en otros puntos del país como Buenos Aires, Córdoba, Rosario, Tucumán o Bahía Blanca); y la proliferación de diversos talleres de producción (de pintura, fotografía, arte urbano, arte gráfico e impreso, etc.) que se realizan en galerías, casas culturales, centros culturales y casas particulares. los productores y gestores de espacios. A su vez, esos proyectos e iniciativas tienen mucho impulso creativo y potencia colectiva pero varias veces terminan como cuerpo profesional o cuerpo de oficio tercerizado del Estado (sobre todo municipal, provincial y la universidad). Así, antes que un trabajo "con otros", mancomunado, muchas veces las prácticas que se activan (con recursos, ideas, tiempos propios) terminan siendo "para otros", por lo general actores institucionales.

También se puede observar que falta una visión política global y estratégica sobre las políticas culturales institucionales — sean estatales o privadas de mediana y gran escala-, problemática común a todas las escenas culturales de la ciudad. En este sentido, es preciso comprender las transformaciones operadas por la globalización de la economía, las modificaciones en las políticas nacionales y locales y la "expansión y capitalización de lo simbólico debido a las innovaciones tecnológicas en las telecomunicaciones y en la industria del entretenimiento [que] han realzado el valor de la cultura como recurso." (Yúdice, 2008, p. 31)

Como síntesis de este punto se puede decir que del rechazo que habitaba en la cultura alternativa local a las ideas y prácticas de la "gestión", se pasó a intentos incipientes de tomarla desde una visión integral en varias de las experiencias locales: organizativa, política, económica y comunicacional. Actualmente, algunos actores locales comienzan a definirse como "gestores culturales" o "agentes culturales". De este modo, junto con las ya referidas nociones de "escena", "circuito" y "cultura emergente"; emergen estas denominaciones de "productor-gestor", "gestor" y "agente cultural" en sus propias retóricas, así como otras nociones del universo de la "gestión cultural" y las "industrias culturales y creativas"; "proyectos" y "convocatorias" a las cuales "aplicar", así como también ciertas ideas de "profesionalización" y de "mercado". Asimismo, se comienza a hablar de las problemáticas de la gestión y la autogestión en diferentes encuentros colectivos, espacios de formación y de debate y foros de articulación. Sobre esto último se trabaja en el siguiente apartado.

\section{Los modos de asociación: encuentro en la dispersión}

Algunas de las situaciones más potentes que se pueden encontrar en la ciudad son las formas dinámicas de asociación y articulación colectiva. La Plata es una ciudad en la que continuamente se construyen tramas de vínculos entre diversos actores, especialmente desde los itinerarios que cruzan el arte y la cultura. 
Antes que "la ciudad" (como una cualidad "innata" o propia de su condición urbanística modernista), se considera que es su cultura urbana la que es un gran caldo de cultivo en ebullición de proyectos compartidos y encuentros colectivos. Solo por dar algunos ejemplos de esto, que se producen desde la organización y coordinación independiente, se puede mencionar al encuentro Ecart y a DanzAfuera, las FLIA (Feria del Libro Independiente y Autogestionada) hace unos años y, más recientes, las diversas "movidas" editoriales y literarias impulsadas por editores independientes y autores (muchos nucleados principalmente en El Espacio), las jornadas "Desbordes" (en las que confluyen diversas disciplinas y proyectos culturales), los tres ámbitos de confluencia de los centros y espacios culturales alternativos -RECA (Ronda de Espacios Culturales Autogestivos), Red de Espacios Culturales y UCECCA (Unión de Centros Culturales Alternativos y Artistas) y el " 1 ${ }^{\circ}$ Foro regional de espacios culturales autogestivos" organizado por esos tres reagrupamientos. En la música rock las masivas movidas en las que participaron bandas, músicos y rockeros en defensa del bar "Pura Vida" frente a los intentos de cierre por parte del Municipio y los diferentes sellos discográficos. Dentro de la escena de las artes visuales, se destaca principalmente el "Encuentro local de espacios y colectivos vinculados a las artes visuales" (organizado por Cama elástica en 2013) y "TOC Artes visuales" (espacio surgido a inicios de 2016 y que forma parte de una asamblea de trabajadores/as de la cultural a nivel local). Sin embargo, hay que señalar que en este aspecto de las articulaciones, donde las formas de encuentro son menos "públicas", ellas están menos volcadas a generar acciones colectivas y más ligadas a los entramados de relaciones personales que se bifurcan en los microcircuitos y micro-comunidades. En comparación, la escena literaria-editorial y la escena de espacios culturales alternativos —en la que también están insertos algunos actores de la escena de las artes visuales - generan mayor visibilidad y discursos públicos "como escena", los cuales se articulan y traducen en "movidas" colectivas, construcción de relatos afirmativos, producción de demandas al Estado - para generar normativas y fondos económicos de promoción cultural a sus actividades-, expresiones identitarias de cualidades, improntas, pareceres y, a veces, posicionamientos sobre la realidad social y política.

Todos estos encuentros, y muchos más, planteados desde las diferentes escenas, forman parte de esas tramas que forjan y movilizan a la "cultura emergente" de la ciudad. De este modo, se entiende que las formas de asociación y organización de las prácticas culturales crean un tejido de relaciones donde, en un grado importante, la amistad y el afecto son parte constitutiva de estas y las sostienen. Asimismo, es en el encuentro sostenido en un trabajo de "hormiga" donde las prácticas culturales constituyen esa trama diversa y compleja de sentidos compartidos, afectividades y acuerdos. En el día a día se crean y recrean esas diferentes escenas integradas por artistas y gestores, músicos y productores, amigos, personas inquietas y comunicadores, editores, escritores y poetas, curadores y productores vinculados a lo visual.

\section{¿Políticas estéticas en la escena local de artes visuales?}

Luego de desandar la caracterización de las escenas culturales de la ciudad, el objetivo de este apartado es ahondar aún más en los contornos de la escena local de las artes visuales. Se retoma nuevamente a Nelly Richard (2014) y su discusión sobre las figuras del arte y el artista "comprometido" construidas en los años sesenta y que actualmente han caído en desuso. Traer a este artículo esta reflexión crítica sobre el desplazamiento de la mirada en relación a las potencialidades transformadoras del arte en el contexto contemporáneo, no es azarosa. Sirve para ilustrar la época contemporánea del arte en sus últimas tres décadas, sus intencionalidades y propuestas, donde lo político es muchas veces re-elaborado, disuelto o negado en "los proyectos", las obras, las muestras, las formas colaborativas en red y las narraciones que se construyen alrededor de dichas iniciativas (García Canclini et al, 2012). Aquí surge una pregunta: para la situación abierta desde los años 2010/2011 en adelante en La Plata ¿podemos hablar de una escena artística sin política?

Como supuesto, se puede pensar que si en los años 70 el énfasis de una obra artística estaba puesto en su contenido y en el rol pedagógico que podía tener - direccionado por el pensamiento político esclarecedor-, se pasó en los años 80 a un momento histórico de "incertidumbres" que persiste hasta el presente. Desde allí muchas prácticas artísticas piensan en sus contextos locales de inserción y en el proceso de creación. En dicho proceso se observa que algunas prácticas artísticas buscan "desmaterializar" el arte y se trazan como objetivo generar una acción participativa con el público o dejar que este re-elabore las propuestas a través de su "experiencia sensible" o también desarrollar procesos colaborativos y de coproducción con comunidades y territorios — con matices y diferencias esto se trabaja en Bourriaud (2006), Ardenne 
(2006), García Canclini, (2010), Laddaga, (2006), Holmes (2008) ${ }^{8}$.

Con los aportes de Rancière $(2010,2011,2014)$ reconocemos que algo del arte siempre es político y viceversa: algo de lo político es estético. Nunca son dos esferas completas y totalmente separadas que luego entran en relación. También, a partir de sus cuestionamientos al "arte crítico" y sus legados, podemos comprender que las querellas en las que se debatían las vanguardias artísticas del siglo XX entre el reclamo de autonomía del arte y la primacía del vínculo con la política (o a veces, la subsunción del arte a la política) no son tales en la actualidad. Para Rancière no hay conflicto entre la búsqueda de autonomía del arte y la politización.

Teniendo presente esta propuesta podemos pensar de qué modo la escena local de artes visuales atraviesa "lo político". En este sentido -si analíticamente es adecuado hablar de "faltantes" y cuestiones pendientes- en la escena de artes visuales platense una de las cuestiones que escasean es conflictividad, hacer bulla, molestar $^{9}$. Ese ruido y molestia no solo en la forma de "reclamo ante el Estado". Tampoco en la forma más radical de rechazo o disputa directa contra las instituciones (algo que, en algunos momentos de la historia,

8 En esta propuesta igualmente se encuentran diferencias en los análisis: Ardenne y Bourriaud cargan a la figura del "artista" como el que recrea y restituye el "lazo social" roto por los procesos de mercantilización y comunicación de la sociedad global. Otros autores privilegian los procesos colectivos donde esa figura del artista muchas veces se disuelve en la trama de mueve una acción. Por su parte, Rancière radicaliza los supuestos y plantea que la estética "es el pensamiento del sensorium paradójico que permite definir las cosas del arte" (2011, p. 22). En cuanto a la figura del público, en la interesantísima propuesta de Rancière (2010) hay que reexaminar el juego de las equivalencias (público y comunidad, mediación y simulacro) y las oposiciones (imagen y realidad, actividad y pasividad), así su hipótesis es que el hecho de espectar no implica ninguna debilidad. Para decirlo a grosso modo, para este autor no hay que molestar ni buscar activar al espectador, este "ya tiene demasiado" con serlo.

$9 \quad$ Una excepción sería la práctica del graffiti que en los últimos años está siendo criminalizada por gobernantes, agencias estatales y medios comerciales de comunicación que fuerzan definiciones y buscan (no sin entredichos y ambivalencias) producir una distinción entre el graffiti (ilegal, vandálico, no-artístico) y el arte urbano (legal, colaborativo, artístico). En 2015 hubo algunas causas contravencionales abiertas por "daños" contra algunos interventores y se aprobó una nueva Ordenanza Municipal ( $\left.N^{\circ} 11237\right)$ que busca regular y reprimir a las pintadas. Lamentablemente es una conflictividad por la negativa y defensiva. emprendieron las vanguardias artísticas ${ }^{10}$. Lo que "falta" en la escena de artes visuales es pensar preguntas y activar propuestas que desacomoden a la propia experiencia y a una escena creativa y heterogénea, pero a veces algo previsible en su estética, en sus formas retóricas, de visualidad y de movilización. Faltan otras vibraciones y queda pendiente aún desarrollar lo productivo del conflicto. En este sentido, la escena carece de estrategias de gestión y comunicación para desarrollar y visibilizar los proyectos: para construir narraciones sobre sus experiencias ${ }^{11}$. Es preciso pensar, pues, a los "públicos", a los que espectan muestras, los que compran obras, los que circulan por galerías y talleres. Y a todos los que lo podrían hacer. Es decir, no solo enfocarse sobre el público afín y conocido que va a "las movidas", si no sobre aquellos sujetos que hoy no van, a fin de buscar que también sean partícipes. Los apartados que siguen presentan las experiencias de Luxor, Cösmiko y Síntoma.

\section{Luxor: encontrando de qué manera hablar}

La experiencia de Luxor puede ser ilustrativa y a la vez contrastante con algunas de las situaciones y tendencias mencionadas hasta aquí en relación a la escena de artes visuales. Es un productor que comenzó a intervenir en la ciudad desde la "pintada callejera" a comienzos de 2010 y rápidamente cobró notoriedad por sus intervenciones visuales, acompañado con el uso de las redes virtuales. Desde inicios de 2013 emprendió el camino por "vivir del arte", situación novedosa para él, ya que comenzó a intervenir en la ciudad sin ese objetivo ${ }^{12}$. Esto lo lleva a cabo por medio de muestras con venta de obra en La Plata, la promoción de obras y acuerdos de ventas por Facebook, el espacio de "almacén de obra" - venta permanente en su taller (actualmente "Obrador 45") - y la realización de muchas de las pintadas callejeras por las que cobra dinero. Es uno de los pocos productores visuales jóvenes de la ciudad

\footnotetext{
10 Estas dos son maneras posibles y, a su modo, ambas son transformadoras para encarar lo político desde el arte: la primera podría ser una demanda que busca formalizarse en las instituciones -modificar o proponer una política pública específica-, la segunda es menos probable actualmente.

11 En relación a los modos de gestión de los proyectos, se puede plantear que es una de las escenas locales que menos desarrollo tiene en relación a esta cuestión: no es viable en el tiempo sostener los proyectos -y a las personas involucradas directamente- desde una economía de la subsistencia.

12 Luxor renunció en 2013 a su empleo como trabajador
} no-docente de la Universidad Nacional de La Plata. 


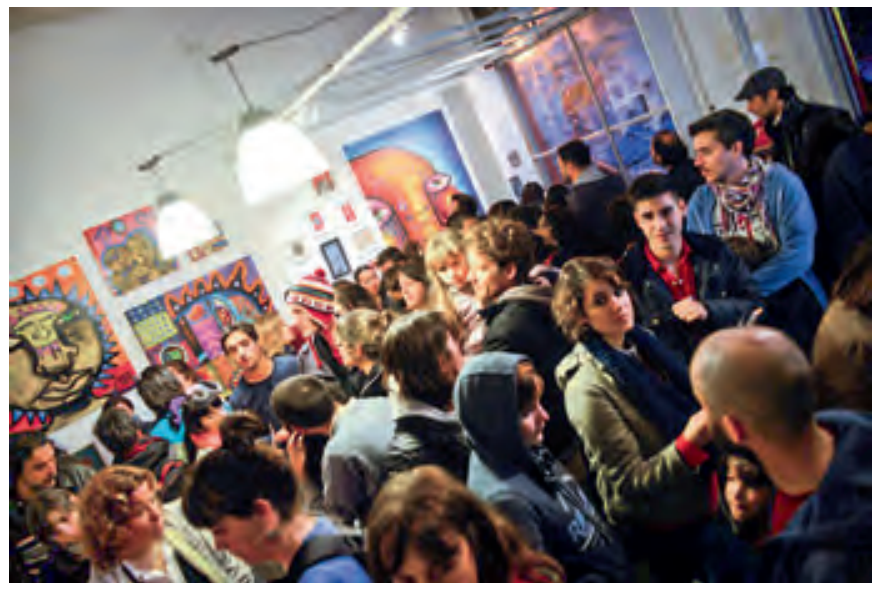

Muestra Lucha libre. Construyendo la fuerza sensible de Luxor en taller-galería Oro (agosto de 2015). Fotografía: Florencia Cariello.

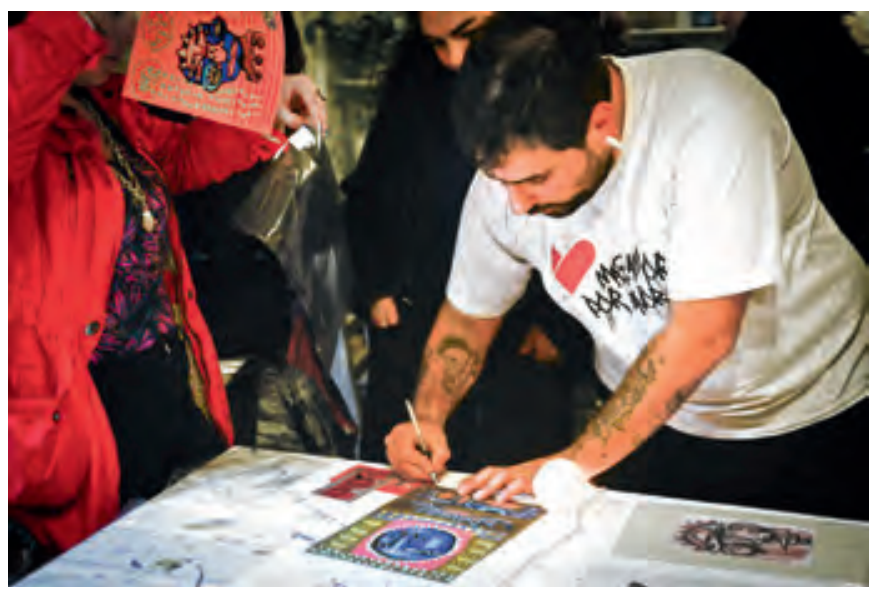

Muestra Lucha libre. Construyendo la fuerza sensible de Luxor en taller-galería Oro (agosto de 2015). Fotografía: Florencia Cariello.

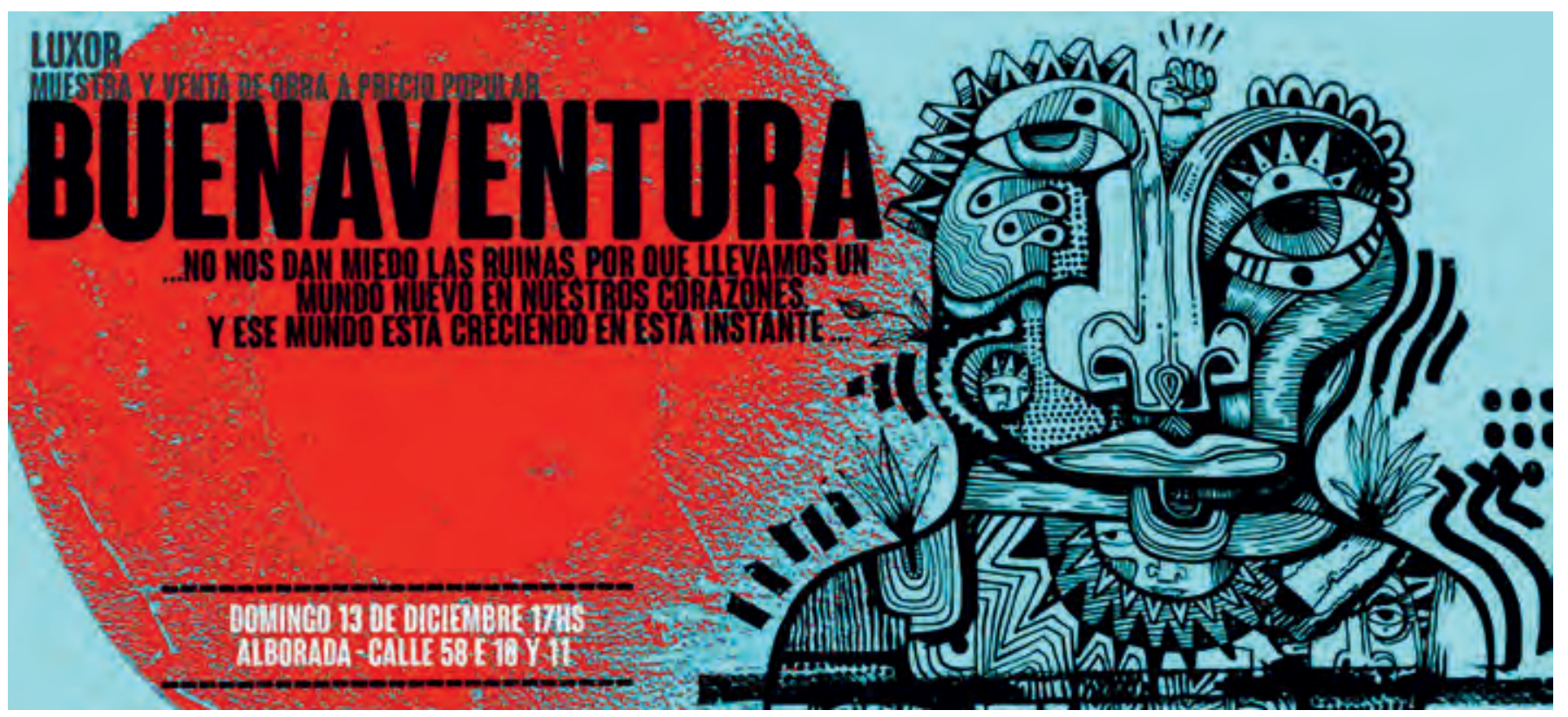

Flyer digital de promoción de la muestra y venta de obra de Luxor, Buenaventura (diciembre de 2016).

que hoy vive de la circulación de su producción, lo que también da cuenta de un modo de vida autogestionado: el mismo es su propio hacedor y gestor. La mayoría de los productores de su generación, en cambio, sustentan sus vidas con otras actividades e ingresos, principalmente vinculadas a la docencia, el trabajo estatal y el dictado de talleres de producción o formación artística en espacios de arte. La venta de obra pasa a ser un recurso secundario. En su hacer cotidiano, Luxor combina las acciones en el espacio urbano y el espacio de muestras para la circulación de sus obras, con un gesto de darle mayor importancia a las primeras. Según él:

Lo que pasa que se fue modificando mucho todo desde que arranqué. Nunca pensé que iba a vivir del graffiti. Yo no empecé nunca con esa idea. (...) Si ves bien, estoy produciendo con re poca guita, vivo con poco dinero. Pero vendo un par de obras y salgo a pintar, pintar, pintar...13

En contraste con lo que sucede con los artistas visuales de la ciudad, Luxor no suele presentarse a becas, subsidios y convocatorias institucionales y tampoco ha terminado una carrera académica vinculada a las artes, dos cuestiones que sí realiza la mayoría de los productores y actores de la escena local ${ }^{14}$. Esto puede

\footnotetext{
13 Entrevista a Luxor, La Plata, marzo de 2013.

14 Luxor estudió los primeros años de la carrera de Grabado y Arte impreso en la Facultad de Bellas Artes de la UNLP.
} 
interpretarse como un gesto anti-académico y anti-las "Bellas Artes". Luxor plantea que en las instituciones consagradas al saber y a la circulación del arte anida lo "estático". A ello se puede sumar su mirada sobre las vanguardias y su propuesta de estar con "la gente", ser parte de la "cultura popular":

No me interesan nada las vanguardias. Yo me considero un pintor callejero. Las vanguardias se alejan de las masas y yo no quiero alejarme de la gente. Si me pusiera a intelectualizar como un vanguardista, perdería tiempo de acción. ${ }^{15}$

Pero Luxor no está ajeno a las cuestiones y modos del arte actual: se posiciona como gestor y coordinador de varias "movidas" colectivas ligadas a lo gráfico y lo visual ("Intervención magenta", "ZigZag", galería de arte de Alborada, "Pantufleta refrescante", "Obrador 45", por mencionar algunas). Esto se relaciona con una de las premisas desde las que se mueve: "la gente piola se junta". Sin embargo, otra cuestión contrastante de Luxor con las posturas e iniciativas actuales en el arte local es que no se reconoce dentro del "arte contemporáneo". Esto es algo que mencionó sobre todo en las conversaciones en 2015: "Lo que yo hago, mi producción, no es arte contemporáneo, no me muevo en ese circuito". Esta (in)postura de no sentirse dentro del espacio de lo contemporáneo en el arte puede ser leída como un intento de correrse de varias situaciones en boga que hoy activan y delimitan gran parte del campo artístico local y nacional. En relación con esto también comentó: “No necesito curadores, mi obra no necesita ser curada"16. Aunque aquí se entiende que tanto en su producción como por su forma de moverse puede tener contactos con esas prácticas y discusiones contemporáneas. En tal sentido, la propia producción de Luxor fue mutando en estos años tanto en las temáticas que trabajó como en sus composiciones y en la ampliación de los formatos - grabados en láminas, estampas en remeras, reproducciones digitales en pequeño formato, obras originales en mediano y gran formato-. "Es que no podés pintar siempre lo mismo. Me gusta modificarlo. Estoy encontrando de qué manera hablar." Luxor modificó la idea de hablar de "disidencia" porque se emparentaba con la idea de "contracultura", lo que en su parecer termina legitimando su contrario: hablando desde y sobre lo disidente "es como que legitimás el espacio que ata-

\footnotetext{
15 "Hay paredes que piden que las pinte", diario El Día, 3/02/2013.

16 Notas de campo, conversaciones con Luxor, La Plata, julio de 2015.
}

cás. ¿Disidente a qué? Estás legitimándolo"17. Esta otra postura de Luxor puede pensarse, primero, como un giro decidido hacia la idea de práctica artística y la consecuente valorización de la "obra" y la "producción" que se realiza. Segundo, como un giro hacia lo contemporáneo en el arte: salirse de los lugares asignados, estar mutando y desplazándose todo el tiempo de lugar. En relación a la valorización de la obra / producción y a los modos de circulación recurrentemente ha comentado que busca producir "obras de calidad" tanto para la persona que solamente la puede pagar con una comida como para la persona que puede pagar miles de pesos por un "Luxor original".

\section{Cösmiko, encuentro de mundos}

Cösmiko se define, por un lado, como una galería de arte y, por otro, como un club de amigos. Su actividad principal es organizar eventos, muestras y talleres de arte con productores de La Plata y de otros lados del país: "siempre con la idea de que intervengan el espacio de exposición, desde el piso al techo". Buscan así propuestas expositivas "que tomen el espacio y lo hagan propio, que no sean solo colgar obra, sea un cuadro o una foto"18. Cösmiko se piensa también como un club de amigos, ya que les interesa tener socios que colaboren con mantener la estructura del lugar. Así, el espacio funciona con dos responsables, pero existe una red de amistades y afinidades que hacen posible todo lo que acontece en el lugar.

El nombre del proyecto surgió "porque cada uno es un mundo y el espacio es una convivencia de cada uno. Una casa abierta a que puedas estar con gente de diferentes palos, sin prejuicios." 19 Por eso, las actividades son diversas aunque siempre relacionadas con el arte.

Los inicios de Cösmiko se remontan al año 2010, donde arrancaron como Activaciön Monastér. En ese tiempo se instalaron en Estación Circunvalación, una pequeña y vieja estación del ferrocarril abandonada sobre la calle circunvalación en el límite del casco urbano de La Plata (12 y 72). La estación fue ocupada por varios jóvenes de la zona y los Monastér gestionaron ahí una galería de arte en la calle orientada al arte urbano. "Lo que más

\footnotetext{
17 Entrevista a Luxor, La Plata, junio de 2014.

18 Entrevistas a Cösmiko, La Plata, diciembre de 2013 y diciembre de 2016.

19 Entrevistas a Cösmiko, La Plata, diciembre de 2013 y diciembre de 2016.
} 


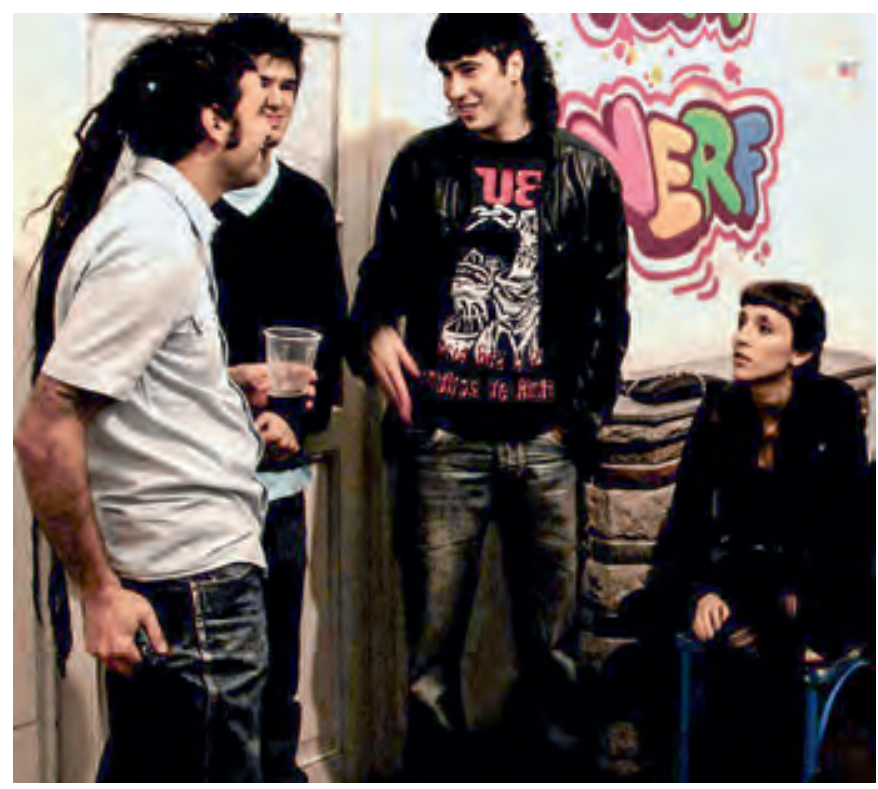

Muestra Pum-pum, Nerf y Valentino Tettamanti en Cösmiko (agosto de 2012). Fotografía: Cösmiko.

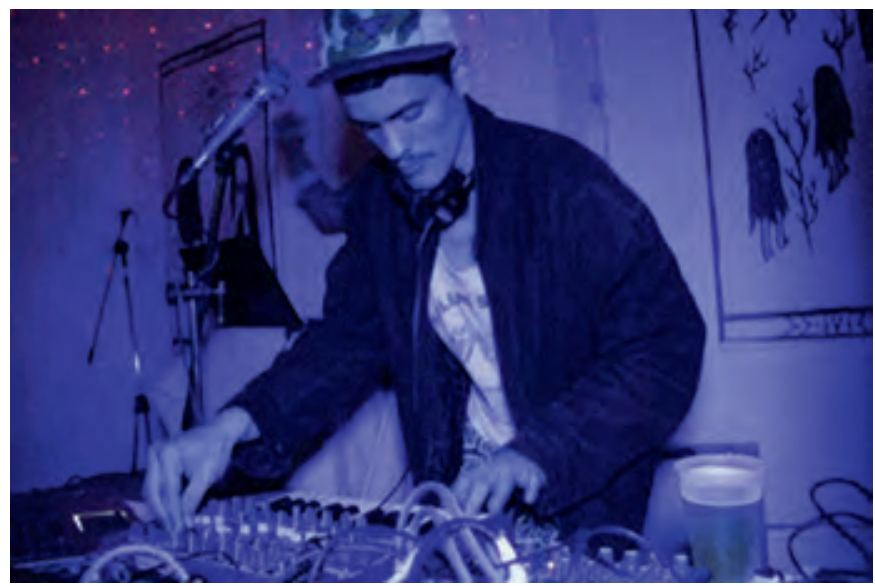

Evento de DJ set y Live set El calor después del calor (junio de 2016). Fotografía: Cösmiko.

queríamos era que el vecino que no entiende la movida pueda acercarse y vea todo lo que se hace. Es más, nos interesa que los eventos convoquen gente nueva, que en sí es el mismo concepto que tenemos en la casa nueva." ${ }^{20}$. $Y$ agregan:

Un día, estábamos ahí sentados y vimos que se alquilaba un local enfrente. Fuimos a averiguar: estaba re barato, super detonado y venido abajo. Lo alquilamos, trabajamos meses arreglando el lugar que tenía hasta garrapatas. Finalmente en 2010/2011 empezó Cösmiko en ese local. Entrevista a Cösmiko, La Plata, diciembre de 2013.
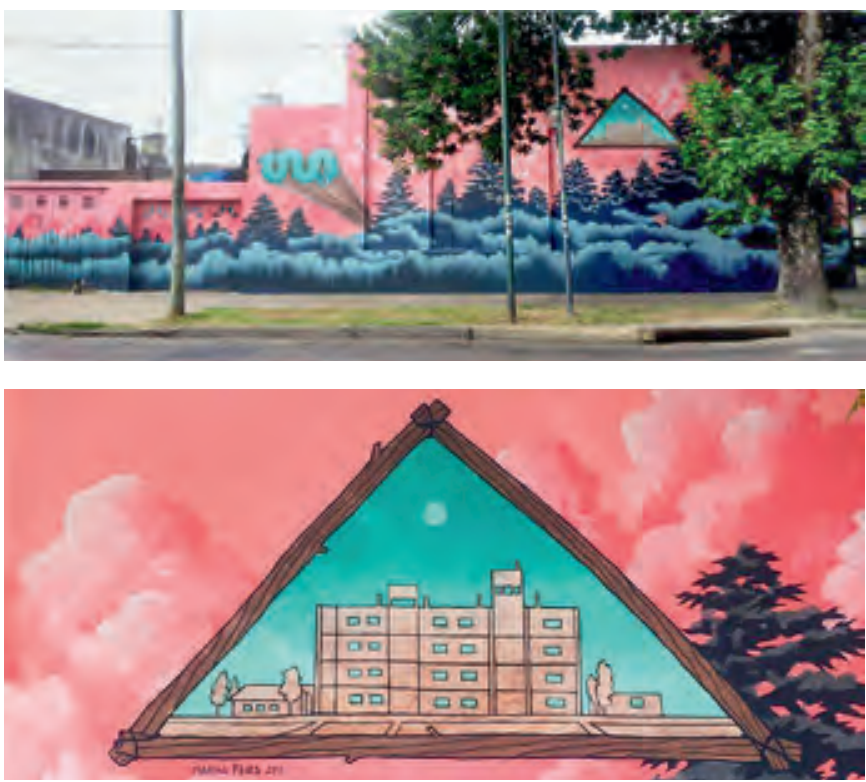

Pintada de Marina Fages en la pared externa (octubre de 2013). Fotomontaje: Kiki Mander.

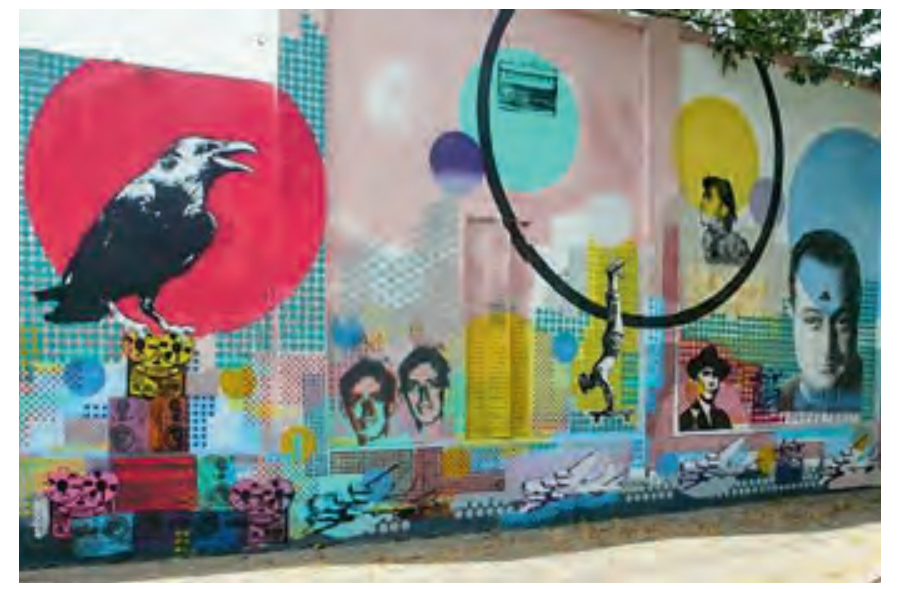

Intervención visual de Dardo Malatesta y Darío Suárez en la pared externa de Cösmiko (abril de 2017). Fotografía: Cösmiko.

$Y$ después se fue armando mejor. Empezamos a conocer más personas y se unieron fuerzas. ${ }^{21}$

Cösmiko surge en sí por el tema que había muchísima gente pintando y por ahí no había espacios en La Plata en donde mostrar que fueran alternativos, había galerías más académicas o para otro

21 Desde Cösmiko recuerdan que "el primer artista que invitamos y encendió la llama de la situación de muestras fue Dardo Malatesta. Él es un pionero en el arte callejero y tiene una galería en Buenos Aires que se llama "Hollywood in Camboya" donde dan clases de stencil y todo tipo de actividades relacionadas con lo urbano. Lo invitamos para que hiciera esa muestra y trajo una banda de gente para la inauguración." (Entrevista a Cösmiko, La Plata, diciembre de 2016). 
tipo de artistas. Y como galerías jóvenes no había y surgió así, invitar a esos artistas a hacer muestras. Cada un mes se cambian las muestras y cada artista hace a su antojo lo que quiera hacer. ${ }^{22}$

Al entenderse como galería de arte, Cösmiko también se dedica a la promoción de distintos productores, a venta de obra y se constituye en mediador entre los artistas visuales y los interesados en adquirir obras. Todas las obras que se exponen en el espacio están a la venta. En relación a las propuestas de muestras y eventos que suceden allí comentan que "nos gusta lo que invitamos. La variedad, la cuestión cósmica, en el sentido de las variedades, de que todo conviva"23. En 2016 Cösmiko cumplió 6 años, 3 en el viejo local y los otros 3 en la actual casa, que queda en la esquina de 10 y 71, en el mismo barrio. Además de las muestras, los talleres, las obras de teatro y las fiestas, forma parte de la casa la peluquería Corte Salvaje. Actualmente, las personas de Cösmiko participan de "La Rosca", un grupo armado con otros espacios de la ciudad —como Octavia V, Casa Ocho y Tormenta Salvaje- y artistas independientes. Es un nucleamiento que "surgió casi sin querer" para conocer y arreglar cuestiones en relación a la ordenanza municipal vigente sobre espacios culturales. ${ }^{24}$

\section{Pensar y potenciar la escena local: La experiencia de Síntoma ${ }^{25}$}

Con un breve enunciado en su página de Facebook Síntoma presenta su propósito: “indaga sobre los dispositivos de exposición y comunicación de las producciones simbólicas". Entre sus objetivos se destaca una búsqueda por intervenir en los conceptos, dispositivos y espacios del campo cultural de la ciudad de La Plata y la escena local de las artes visuales. Su presentación e instalación fue en 2012 con la organización de siete muestras y la participación en el armado del encuentro "ZigZag" junto con Luxor y otros productores y gestores

22 Entrevista a Cösmiko, La Plata, diciembre de 2013.
23 Ibidem.
$24 \quad$ "Estábamos averiguando cuestiones legales de una ordenanza
para espacios culturales de la ciudad y cuando hablábamos con otras
personas o grupos siempre salía la palabra "rosca". Se decía, "tenés
que estar en la rosca" o "no tenés que estar en la rosca". Y decidimos
armar nuestra "rosca", una rosca abierta, con la idea de unir fuerzas
y estar más armados que nunca." Entrevista a Cösmiko, La Plata,
diciembre de 2016.
$25 \quad$ Un trabajo de análisis pormenorizado sobre Síntoma se
encuentra en López, 2015.

de la ciudad ${ }^{26}$. Esas muestras conformaron un ciclo bastante compacto, en diálogo con los llamados "interlocutores"27, donde Síntoma marca su intención de "incidir" activamente en los circuitos alternativos de producción, circulación y validación de las artes visuales. ${ }^{28}$ Para ampliar una definición de lo que pretenden, desde el grupo plantean:

Síntoma básicamente es una cuestión de ethos, de una voluntad de incidir sobre el campo cultural, en el cual nosotros estamos vivos, estamos trabajando (...) el dispositivo mismo, toda la forma de abordar ese dispositivo es Síntoma. Es algo que en algún punto piensa la manifestación de algún tipo de estructura.

(...) Aterrizamos al campo, por A, B o C, ya validados; en un cierto sector que estamos operando. La ausencia de otros competidores, si se quiere,

26 En noviembre de 2011 este colectivo participó en la curaduría y el montaje de la muestra "Caminantes. Luxor te la muestra", la primera muestra individual de ese productor. En aquel entonces esta actividad no estuvo mencionada como propia de Síntoma, pero puede ser interpretada como inicio del grupo.

27 Es interesante observar que la mayoría de los productores seleccionados por Síntoma para esas muestras -Acra, RayMund, Pantera, Cons, Nelson y Luxor - son participantes activos del circuito local del "street art", el "graffiti" y la "pintada callejera", actores cuyos itinerarios de obras y acciones se dan "en la calle" y cuyo principal soporte es la pared — sea de espacios públicos o privados-y no los dispositivos del formato muestra y los espacios de galería. Ahí se puede encontrar una marcada intencionalidad de Síntoma para que esos productores se pongan a jugar en un terreno específico del campo artístico, en una escena local de las artes visuales. En este sentido es que podemos entender a estos productores locales, tomando las categorías de Bourdieu $(2002,2014)$, como los agentes con menos "volumen de capital", quienes ocupan la posición de "recién llegados" al campo y deben generar sus estrategias para permanecer $y$ consolidarse.

28 Tomando la literatura disponible dedicada al "arte contemporáneo" y a los circuitos de exposición y legitimación, resulta interesante el aporte de Raymonde Moulin, quien plantea —casi en oposición - las lógicas de diferentes tipos de galerías. Por un lado, "las galerías que se dedican al arte tradicional, en función de la selección de artistas que realizan, evitan la toma de riesgo que se asocia a la innovación" y supeditan la elección de artistas por el pode adquisitivo de su clientela y a la rotación rápida del stock; por el otro, las galerías que se dedican al arte contemporáneo ponen en práctica un "circuito de valoración cultural". La ecuación, así, es inversa: fabricación de la demanda contra sumisión a la demanda (Moulin, 2012, pp. 32-33). Ampliando el concepto - ya que la autora se centra en analizar el "mercado del arte" en el que las galerías cumplen un rol importante-, podemos pensar que no solo las galerías participan de su circuito de valoración cultural, sino también otros espacios y actores que se implican en la presentación y circulación de las obras y prácticas artísticas. 
nos da una facilidad total. Buscamos incidir en el campo. Esto [se refieren a la construcción de muestras] es el plan de mínima de todo lo que pasa en La Plata, no de máxima. La idea es que empecemos a discutir otras cosas. ${ }^{29}$

En este sentido, en los siguientes años, entre 2013 y 2015 , sus prácticas se ligaron a la lectura, la crítica y la reflexión sobre muestras y sobre la escena misma. Esto se materializó en un espacio de reseñas, la curaduría de algunas muestras colectivas, algunas placas virtuales, un conversatorio y la constitución de una agenda. Síntoma se desplazó para jugar en el plano de la reflexión, instalando ejes de debate y pensamientos sobre el contexto emergente y propuso activar la mirada sobre las exposiciones, tanto del circuito oficial como alternativo de galerías y espacios de arte en la ciudad.

Hacíamos curaduría por una forma de pensar diferente la escena platense, lo que decíamos "no colgar los cuadritos", no era por la curaduría como montaje en sí mismo, sino que en realidad apuntábamos a lo mismo que apuntamos ahora. Incidir en lo que eran las prácticas, que veíamos como dominantes, que dejaban relegado para otro momento tomar en consideración todo lo que interviene en la producción simbólica, que no es solamente colgar un cuadro y ver cómo se lo presenta, sino tomar el circuito entero y pensarlo. (...) En eso lo primero era ponerlo en valor (...), un primer paso de conocimiento del campo, lo básico era una muestra. Una vez que vimos que ya era una preocupación paralela de otros espacios eso ya nos dejó de ser un paraguas. ${ }^{30}$

Síntoma entiende que en las muestras desarrolladas en la ciudad los últimos años, hubo saltos cuantitativos y cualitativos, algo cambió y sirvió para cuestionar una visión más global: "Lo que uno monta no termina en la galería, sino que tiene mucha importancia en la escena donde uno lo monta"31. Algunas de las acciones del grupo generaron disparadores para la producción de muestras y reflexiones dentro de la escena y la apertura de conversaciones entre actores diferentes. En tal sentido apuntan:

Comenzamos a observar que había muestras que estaban proponiendo lo que nosotros ya veníamos

\footnotetext{
29 Entrevista a Síntoma, La Plata, noviembre de 2012

30 Entrevista a Síntoma, La Plata, abril de 2014.

31 Entrevista a Síntoma, La Plata, abril de 2014.
}

planteando en esa primera etapa, podríamos decir. Entonces nos pareció que hacía falta mirar desde afuera esas muestras, hacer un análisis de lo que estaba sucediendo, de por qué se estaban haciendo y empezar un poco a poder ver, a cartografiar y a definir esas experiencias para definir una escena, para empezar a vernos como una escena. Lo que en un principio fue como un núcleo donde nosotros empezamos a hacer muestras, curando las muestras, terminó siendo todo un año de no hacer ninguna curaduría sino de estar mirando qué era lo que estaba sucediendo y plantear ya la curaduría no sólo de una muestra sino de una escena. ${ }^{32}$

Para Síntoma, en la escena hay actualmente un "movimiento de autovaloración", de nuevas referencias, donde se amplían los espacios de exposición, se comienzan a visualizar en los medios locales y se incluye un significativo número de investigadores del arte, junto a otros grupos que están también haciendo análisis sobre estos temas. A su vez, afirma que la "estética platense" es "una estética tensionada"33. Así, acuñan la categoría "preciosismo conceptual" para pensar la escena local desde una visión global. Se trata de una categoría provisoria y para seguir trabajando, que se tensiona entre un polo conceptual y un polo "preciosista", ligado al oficio ${ }^{34}$. Otro elemento que hace a cierta "especificidad platense" es la posibilidad de las

32 Entrevista a Síntoma, La Plata, abril de 2014.

33 Según Síntoma, esta tensión está asociada a las "instituciones existentes" —como la Facultad de Bellas Artes y los museos oficiales-, la gran cantidad de talleres de arte, las prácticas estéticas ligadas al espectro militante (las organizaciones sociales que trabajan en el campo del arte y política), a la pintura, el grabado, el dibujo - por lo general de pequeño formato, en donde "lo técnico es llevado al extremo"-, a ciertas figuras del graffiti así como a las "promesas" de mercado del arte. Entrevista a Síntoma, La Plata, abril de 2014.

34 Ante "un binomio de opuestos, que en cualquier discurso parecerían irreconciliables" Síntoma plantea que "lo interesante en La Plata es que no son opuestos e irreconciliables, es la escena la del 'preciosismo conceptual'". Existen tensiones fuertes hacia alguno de los polos "pero no se desconocen, se pelean, se encuentran, a veces tienen aciertos, a veces desaciertos. (...) No es una tensión intrínseca entre actores que no se ven. Son actores que se ven, se tocan y generan una energía particular" Entrevista a Síntoma, La Plata, abril de 2014. En tal sentido, estos movimientos se transforman en reajustes y acomodaciones dadas por los encuentros plenos de tensiones. 
conexiones que habilitan a "trabajar la red"35, lo que se relaciona con la propuesta de Síntoma de ampliar los diálogos y el campo de escuchas e intercambios. En este sentido, buscan ampliar sus "interlocutores" e "ir por el todo". Esto los llevó a focalizarse en los espacios y los gestores que son los que aglutinan a los artistas y productores; y se articula con una mirada del arte que discute la concepción moderna: "la obra no la hace ni la termina un artesano del arte. Se arma con un montón de sujetos, es un ensamble que lo hace la escena"36. A su vez, la búsqueda no solo es en relación con los actores propios del campo artístico, sino también con la reflexión sobre cómo desde "lo social" se interpela "al campo arte". Para Síntoma "fuera del campo del arte" existe una discursividad que puede enunciar interesantes preguntas, metáforas y posiciones. Esta propuesta generó diferentes tensiones y debates, respuestas y réplicas ${ }^{37}$.

En la intención nuestra hay un cruce de cosas (...) empoderar la escena en un doble movimiento si se quiere: empoderar la escena propia a través de que los demás actores, periféricos, que se relacionan indirectamente, empiecen a tener derecho a hablar de esa escena, como a la inversa, que esa escena se deje hablar por cosas de otros campos. $^{38}$

Se puede reconocer en la propuesta de Síntoma un "estado de Beta permanente", un estado de mutación, escucha y creación, e incluso de incertidumbres. Sin embargo, en esa plasticidad de sus acciones hay una claridad de intervenir sobre lo real, activar en el propio presente, produciendo ajustes y apropiaciones: "hay pequeños estallidos y pequeñas cosas que van saliendo", "la idea es siempre estar probando, vas tirando muchas líneas en una dirección"39. Por todo ello,

35 "Van apareciendo agentes nuevos en la ciudad, espacios (...) Nuestra idea sería poder seguir ampliando y seguir trabajando esa idea de 'trabajar la red' con nodos e ir tocando personas cercanas a nosotros pero para que toquen a otros, que vaya haciendo como una cadena, para no quedar acotados. Para no quedar en el amiguismo, o explotar el amiguismo, la potencialidad del amiguismo, un amiguismo que llame a otro amiguismo. Convocar a personas que convoquen a otras personas para no quedar en un círculo de conocidos." (Entrevista a Síntoma, La Plata, abril de 2014).

36 Entrevista a Síntoma, La Plata, noviembre de 2012.

37 En esos años (2013-2014) el espacio de las "reseñas" que el colectivo llevó adelante se transformó en, prácticamente, la única propuesta de "producción de textos" sobre muestras, obras y situaciones vinculadas a la escena local.

38 Entrevista a Síntoma, La Plata, abril de 2014

39 Ibidem. se entiende que el empoderamiento de una escena es un elemento decisivo para que esta se reconozca como un actor generador de producciones, acciones y situaciones significativas ${ }^{40}$.

\section{Palabras finales}

Considerando los apartados anteriores, se puede afirmar que en el caso de Luxor se reconoce un proyecto autogestivo que busca "vivir del arte", por medio de organizar espacios, eventos y "movidas" de venta de obra para que asistan personas interesadas en su producción y que se encuentran, muchas veces, por fuera del público del circuito artístico. Su objetivo también es un cruce con lo que se encuentra más allá de lo legitimado como propio del arte. A su vez, conecta su producción para el formato galería con la destinada a los espacios urbanos y a las casas particulares. Luxor configura cotidianamente una dinámica particular de habitar la ciudad, de construir su "propia poética" y de poner en circulación su producción. Respecto de la escena local, Luxor interviene y se mueve como un productor visual y gestor que fortalece - principalmente- redes locales de contactos e intercambios por donde su producción y la de otros productores circula y se renueva.

En Cösmiko, las redes de afinidad son el principal fundamento para llevar adelante la experiencia que busca encontrar "mundos", hacer constelaciones diversas. A su vez, busca ser parte e intervenir en la escena local de las artes visuales y tender diálogos con otras escenas y actores, principalmente con el circuito alternativo de Buenos Aires, pero también con otras localidades de la provincia.

Síntoma, por su parte, pone en escena la riqueza y complejidad de la producción cultural y artística local, compuesta por actores y prácticas diversas, por entrecruzamientos de estéticas y discursos diferentes, por la construcción de redes afectivas y de afinidad y por las dislocaciones respecto de las políticas culturales institucionales. Este colectivo constituye una experiencia

\footnotetext{
$40 \quad$ Ese empoderamiento se ampliará también cuando se reconozca vinculada a otras escenas y prácticas culturales que desandan sus apuestas en la ciudad. En este sentido es que podemos pensar en ciertas "formaciones culturales" (Williams, 2009), que se generan y potencian "por fuera" de las instituciones formales, constituyéndose en movimientos, tendencias y espacios efectivos de creación colectiva e incidencia local.
} 


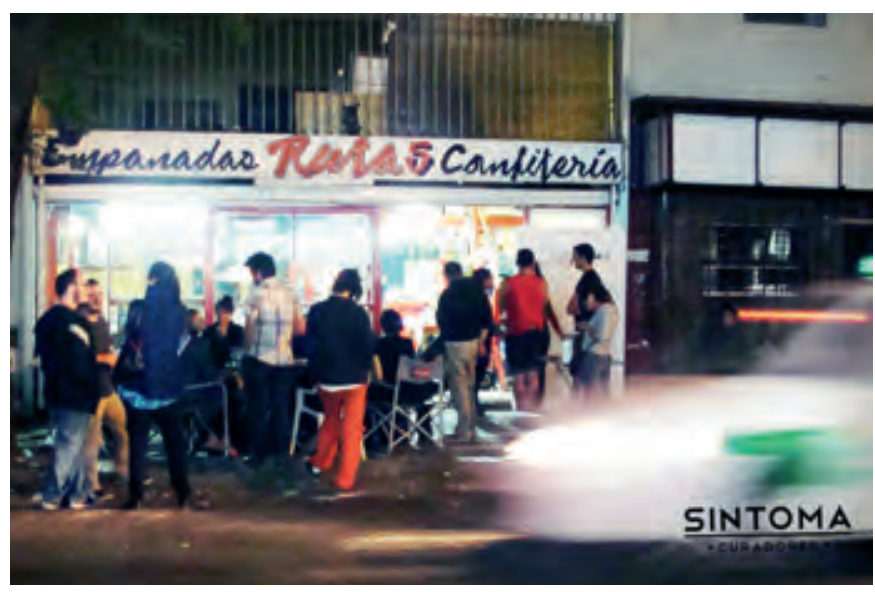

Muestra Todavía no llegó el cocinero / Ruta 5 (diciembre de 2012). Fotografía de Dieguillo fotografió para Síntoma.

situada y renovadora que tensiona "lo propio" del campo del arte — de sus nociones, figuras, metáforas, modos y actores legitimados-. Esto se logra lo hace al poner en entredicho ciertos esos sentidos y lugares asignados, al incorporar a "otros" para hablar del arte -y más que arte- y al buscar volver a repartir lo sensible, las formas de enunciar y mirar.

Como cierre, se puede afirmar que las experiencias de Síntoma, Luxor y Cösmiko tienen vasos comunicantes, sobre todo al cuestionar los lugares comunes en los que se constituye el campo artístico, y en particular la escena local de las artes visuales. A su vez, tienen en común una mirada atenta a las tensiones y a los conflictos que son parte de lo social, y dentro de este del campo específico de la cultura y el arte.

Sin embargo, las propuestas de Luxor y Cösmiko son menos conceptuales que la de Síntoma. En Luxor se encuentra una iniciativa que pretende acercar de un modo alternativo las formas artísticas visuales - composiciones, obras, miradas, procedimientos-a las dinámicas y los consumos "populares", insertar o hacer parte a esas propuestas y producciones en la "cultura popular". Por su parte en Cösmiko la principal iniciativa gira en torno a generar un espacio donde sucedan formas artísticas diversas. Tanto Luxor como Cösmiko se plantean la autogestión no solo como una cuestión de principios, sino también desde el plano más material: entender a la producción, gestión y circulación del arte como "forma de vivir", un aspecto que no ha sido trabajado en Síntoma.

Con todo lo expuesto hasta aquí, sostenemos como supuesto, a continuar trabajando, que se está gestando

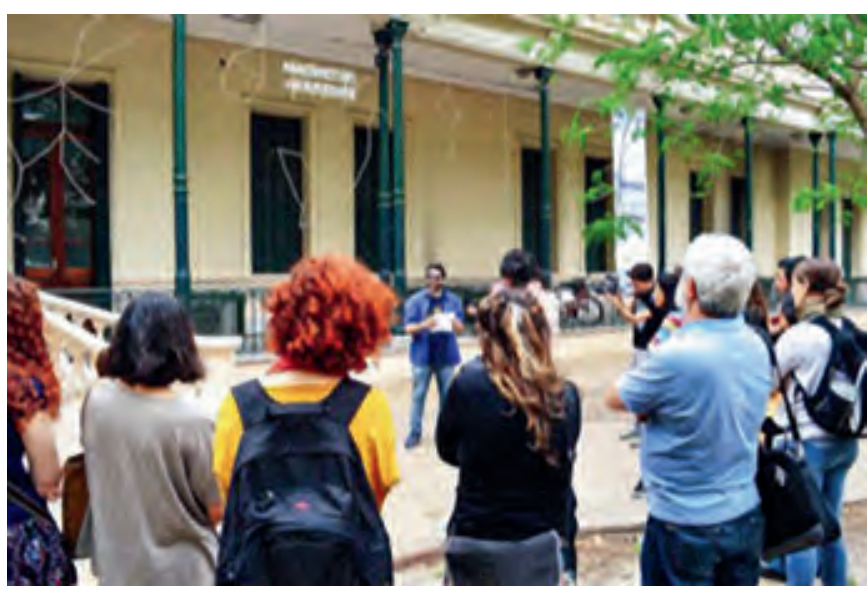

Desencuentros, un paseo por el patio del arte en la III Bienal de Arte y Cultura de la UNLP (octubre de 2014). Fotografía: autor.

- desde 2010/2011- una novedosa escena emergente de producción, gestión y circulación de las artes visuales que renueva el campo cultural por la introducción y constitución de nuevos actores -entre artistas o productores, gestores, curadores, investigadores, comunicadores y públicos- y por la apertura de nuevos espacios de arte y galerías para muestras, venta de obras, talleres, encuentros. Se sugiere así que se está configurando una formación cultural "emergente", alejada de los espacios de decisiones de las instituciones culturales estatales (tanto a nivel municipal y provincial como en el universitario) y ligada a idearios y prácticas de alternatividad, autogestión e independencia. Teniendo en cuenta la propuesta crítica de Rancière $(2010,2011,2014)$ para pensar el hacer político y la estética, podemos interpretar que las tres experiencias analizadas en este artículo se proponen constituir una "estética del disenso"; poniendo en juego allí una dimensión ética y política. Ante el consenso estético que proponen las instituciones del arte, que clausuran la posibilidad de crítica e instauran "la normalidad", estas prácticas y actores locales "emergentes" se posicionan críticamente desde otro lado y configuran una singular cartografía cultural.

\section{Referencias}

Ardenne, P. (2006). Un arte contextual. Creación artística en medio urbano, en situación de intervención, de participación. Murcia: Cendeac.

Boix, O. (2016). “Una socióloga en un mundo de la música: usos de la investigación etnográfica en la profesionalización de un sello musical emergente de 
la ciudad de La Plata" En: Arias, Ana Carolina y Matías David López. Indisciplinas. Reflexiones sobre prácticas metodológicas en Ciencias Sociales. La Plata, Club Hem / IICom (FPyCS-UNLP).

(2013). Sellos emergentes en La Plata: Nuevas configuraciones en los mundos de la música. (Tesis de posgrado). Facultad de Humanidades y Ciencias de la Educación (UNLP). Recuperado de: http://www.memoria.fahce.unlp.edu.ar/tesis/te.1015/te.1015.pdf

Bourdieu, P. (2014 [2003]). El sentido social del gusto. Elementos para una sociología de la cultura. Buenos Aires: Siglo XXI.

(2002). Campo de poder, campo intelectual.

Buenos Aires: Montressor.

Bourriaud, N. (2006 [1998]). Estética relacional. Buenos Aires, Adriana Hidalgo.

García Canclini, N. (2010). La sociedad sin relato. Antropología y estética de la inminencia. Buenos Aires: Katz.

García Canclini, N., F. Cruces y M. Urteaga Castro Pozo. (2012). Jóvenes, Culturas urbanas y redes digitales.

Prácticas emergentes en las artes, las editoriales y la música. Madrid / Barcelona: Ariel / Fundación Telefónica / UAM.

Holmes, B. (2008). "Investigaciones extradisciplinares". Brumaria, 8. Recuperado de: http://eipcp.net/ transversal/0106/holmes/es

Laddaga, R. (2006). Estética de la emergencia. La formación de otra cultura de las artes. Buenos Aires: Adriana Hidalgo.

López, M. (2017). Cambio de piel. Intervenciones culturales, acción colectiva y politicidad emergente en el espacio público de La Plata. Tesis Doctoral. FPyCS-UNLP. Recuperado de: http://sedici.unlp.edu.ar/ handle/10915/59307

(2015). “Breves viajes al país de Síntoma. Provocación, visibilización y régimen estético en la escena de artes visuales de La Plata (provincia de Buenos Aires)", Revista Latina de Sociología, 5 , pp. 78-102.
(2013). "Lugares de vida. Nueva escena de espacios culturales emergentes de exhibición en la ciudad de La Plata", en Fernández, M. y López, M. Lo público en el umbral. Los espacios y los tiempos, los territorios y los medios. La Plata: EPC y IICom (UNLP), pp. 189-218.

Martín-Barbero, J. (2004). Oficio de cartógrafo. Buenos Aires: FCE.

Moulin, R. (2012 [2003]). El mercado del arte. Mundialización y nuevas tecnologías. Buenos Aires: La Marca.

Rancière, J. (2014 [2000]). El reparto de lo sensible. Estética y política. Buenos Aires: Prometeo.

(2011 [2004]). El malestar en la estética.

Buenos Aires, Capital Intelectual. (2010 [2008]). El espectador emancipado.

Buenos Aires: Manantial.

Richard, N. (2014). "Lo político en el arte: Arte, política e instituciones", E-Misferica, 6.2. Recuperado de: http:// hemi.nyu.edu/hemi/es/e-misferica-62/richard

(2007). Fracturas de la memoria. Arte y pensamiento crítico. Buenos Aires: Siglo XXI.

(2006). "La escena de Avanzada y su contexto histórico" en Mosquera, Gerardo (Ed.) Copiar el edén: Arte reciente en Chile. Santiago de Chile: Puro Chile.

Saez, M. (2016). "Potencia de la contradicción". En Revista Boba, 2. pp. 71-74

(2015). "Ser/estar en el aire-Ser-estar en el suelo. Apuntes sobre la espacialización y el extrañamiento corporal en el proceso de investigación". En: AA.VV. Hacer espacio. Circulaciones múltiples entre cuerpos y palabras. La Plata: Ecart y Club Hem.

Williams, R. (2009 [1977]). Marxismo y literatura. Buenos Aires: Las Cuarenta.

Yúdice, G. (2008). “La globalización y la nueva división internacional del trabajo cultural" En Lacarrieu, Mónica y Marcelo Álvarez (comp.). La (indi)gestión cultural. Una cartografía de los procesos culturales contemporáneos. Buenos Aires: La Crujía. 


\section{Entrevistas}

Luxor, (marzo, 2013), (junio, 2014). La Plata.

Luxor, (julio, 2015). Notas de campo, La Plata.

Cösmiko, (diciembre, 2013), (diciembre, 2016). La Plata.

Síntoma, (noviembre, 2012), (abril, 2014). La Plata.

\section{Enlaces web}

Luxor: https://www.facebook.com/cosmikogaleriaclub/ y http://soyluxor.com.ar/

Cösmiko: http://cosmikogaleria.blogspot.com.ar/ y https://www.facebook.com/cosmikogaleriaclub

Síntoma: https://www.facebook.com/sintomacuradores y https://issuu.com/sintoma/ 